\title{
Influência do plantio de gramíneas na camada de cobertura de aterro sanitário no fluxo de gases
}

\author{
Influence of Grass Planted in a Landfill Cover Layer on Gas Flow
}

\author{
Gemmelle Oliveira Santos ～Francisco Suetônio Bastos Mota
}

Data de entrada: 28/05/2012 | Data de aprovação: 18/10/2012

\section{Resumo}

O objetivo dessa pesquisa foi avaliar a influência do plantio de gramíneas na camada de cobertura convencional de uma célula experimental de resíduos sólidos sobre o fluxo de $\mathrm{CH}_{4}$ e $\mathrm{CO}_{2}$ para a atmosfera. Os capins estudados (Andropogon, Mombaça, Buffel, Massai) e a grama (Bermuda) apresentaram uma capacidade diferente de reter as emissões dos gases (Mombaça: média de 2,5\% de $\mathrm{CH}_{4}$ e 5,0\% de $\mathrm{CO}_{2}$; Massai: $1,9 \%$ de $\mathrm{CH}_{4}$ e 3,8\% de $\mathrm{CO}_{2}$; Andropogon: 0,7\% de $\mathrm{CH}_{4}$ e 1,4\% de $\mathrm{CO}_{2}$; grama Bermuda: $0,6 \%$ de $\mathrm{CH}_{4}$ e $1,1 \%$ de $\mathrm{CO}_{2}$; Buffel: $0,2 \%$ de $\mathrm{CH}_{4}$ e $0,5 \%$ de $\mathrm{CO}_{2}$ ). Os fluxos mássicos e volumétricos também foram menores no solo cultivado com capim Mombaça e maiores no capim Buffel e isso manteve relação com as principais características morfogênicas, estruturais, produtivas e nutricionais utilizadas na avaliação da sobrevivência e desenvolvimento dos cultivos.

Palavras-chave: gramíneas, camada de cobertura, fluxo de gases

\section{Abstract}

This study was aimed to assess the influence of grass planted in the cover layer of an experimental, conventional solid waste disposal cell on the release of $\mathrm{CH}_{4}$ and $\mathrm{CO}_{2}$ to the atmosphere. The studied grasses (Andropogon, Mombasa, Buffel, Massai and Bermuda) showed a different ability to retain gas emissions (Mombasa: averaging 2.5\% $\mathrm{CH}_{4}$ and 5.0\% $\mathrm{CO}_{2}$; Massai: $1.9 \% \mathrm{CH}_{4}$ and 3.8\% $\mathrm{CO}_{2}$; Andropogon: $0.7 \% \mathrm{CH}_{4}$ and $1.4 \% \mathrm{CO}_{2}$; Bermuda: 0.6\% $\mathrm{CH}_{4}$ and $1.1 \% \mathrm{CO}_{2}$; Buffel: $0.2 \% \mathrm{CH}_{4}$ and $\left.0.5 \% \mathrm{CO}_{2}\right)$. The volumetric and mass flows were also lower in the soil with Mombasa grass and greatest in the soil with Buffel grass. This was related to the main morphogenesis, structural, productive and nutritional features used in the assessment of the survival and development of the different grasses.

Keywords: grasses, cover layer, gas flow

Gemmelle Oliveira Santos*

Doutorando em Saneamento Ambiental pela Universidade Federal do Ceará (UFC)

Professor do Departamento de Química e Meio Ambiente do Instituto Federal de Ceará (IFCE), Campus Fortaleza.

Francisco Suetônio Bastos Mota

Doutor em Saúde Ambiental

Professor do Departamento de Engenharia Hidráulica e Ambiental da Universidade Federal do Ceará

Membro da Academia Cearense de Ciências.

*Endereço: Av. 13 de Maio, 2081, Benfica, Fortaleza-CE, 60040531, Brasil - Tel: 55 (85) 3307.3646, gemmelle@ifce.edu.br 


\section{Introdução}

Conforme os estudos (Johannessen, 1999; Popov, 2005; Aye e Widjaya, 2006) os aterros geram preocupações ambientais relativas à eliminação de resíduos, principalmente no que diz respeito à poluição da água, odores, risco de explosão, danos à vegetação e emissão de Gases de Efeito Estufa (GEE).

Os GEE gerados em aterros sanitários, especialmente metano $\left(\mathrm{CH}_{4}\right)$ e dióxido de carbono $\left(\mathrm{CO}_{2}\right)$, alcançam a atmosfera durante o preenchimento do aterro, por processos de percolação nas camadas de cobertura e através dos sistemas de drenagem vertical. Alguns estudos internacionais (Huber-Humer e Lechner, 1999; Hedge, Chan e Yang, 2003; Ishigaki et al., 2008) observaram variados fluxos de $\mathrm{CH}_{4}$ e $\mathrm{CO}_{2}$ pelas camadas de cobertura.

No Brasil, estudos sobre essas emissões (Maciel, 2003; Guedes, 2007; Fernandes, 2009; Berto Neto, 2009) também apontam para fluxos que variam em função de diversos fatores: tipo de área de disposição, características físicas dos solos aplicados nas camadas, forma de compactação dos RSU, idade dos resíduos, estação do ano, horário de medição, altura das camadas de resíduos, questões de pressão e temperatura interna-externa do aterro etc.

A emissão desses gases pela camada de cobertura é uma prática insustentável, representa desperdício de uma importante fonte de energia renovável e contribui para o agravamento das mudanças climáticas, trazendo riscos à integridade do clima. Combater essas emissões não é tarefa simples em função da inadequação dos aterros sanitários para o desenvolvimento de pesquisas aprofundadas sobre esse tema, o que justifica a construção de células experimentais; onde é possível controlar sistematicamente a quantidade e qualidade dos RSU, acompanhar os processos de espalhamento, compactação e recobrimento, estabelecer a altura ideal da camada de resíduos, do sistema de cobertura entre outros cuidados.

Nessa pesquisa, uma Célula Experimental (CE) foi instalada numa área virgem do Aterro Sanitário Metropolitano Oeste de Caucaia (ASMOC), Região Metropolitana de Fortaleza, para permitir o plantio de sementes de gramíneas sobre sua camada de cobertura convencional (solo natural) e avaliação da influência desses cultivos nas emissões de $\mathrm{CH}_{4}$ e $\mathrm{CO}_{2}$ para a atmosfera.

\section{Materiais e Métodos}

\section{A Célula Experimental}

A célula experimental (CE) foi instalada no sudoeste do ASMOC; aterro que começou a operar em 1991 com os RSU coletados no município de Caucaia e a partir de 1998 com os RSU de Fortaleza.

A área cedida para a CE tinha $225 \mathrm{~m} 2$ (15 metros de comprimento x 15 metros de largura) e para otimizar sua ocupação optou-se pelo método da trincheira, que também trouxe menor custo, maior segurança (pessoal e ambiental) e relativa facilidade de operação. Conforme Gomes e Martins (2003) esse método é adequado para recepção de pequena quantidade de resíduo.

A CE recebeu 440 toneladas, sendo o processo de pesagem realizado em balança rodoviária eletrônica existente na entrada do ASMOC e a cobertura desses resíduos se deu com a conformação de uma camada solo compactado de $60 \mathrm{~cm}$ de espessura. 0 solo foi classificado como silto-argiloso, medianamente plástico e com as seguintes características: entre 23 - 29\% de argila, 30 - 35\% de silte, 18 - 24\% de areia fina, 11 - 18\% de areia média, 4 - 5\% de areia grossa, 1 - 4\% de pedregulho, limite de liquidez entre $27-31 \%$, limite de plasticidade entre 13 - 17\% e índice de plasticidade entre 12 - 15\%, umidade ótima entre 11,100 - 12,200\%, massa específica seca entre 1,989 - 2,008 g. $\mathrm{cm}^{-3}$ e permeabilidade à água entre 2,0 - 3,4 x $10^{-5} \mathrm{~cm} \cdot \mathrm{s}^{-1}$.

\section{O Plantio de gramíneas sobre a cobertura da CE}

O plantio das gramíneas exigiria a preparação preliminar do solo da cobertura, porém esse procedimento não foi realizado mantendo-se assim a originalidade e semelhança da cobertura com as condições típicas dos aterros sanitários. Em seguida, uma área de 09m2 foi reservada para cada cultivo além dos espaços deixados como "corredores" para facilitar o processo de irrigação (manual) e evitar o transporte de sementes pelo vento de uma cultura para outra (contaminação).

A escolha das sementes se deu após revisão de literatura, leitura de catálogos, visitas à Empresa de Assistência Técnica e Extensão Rural do Ceará (EMATERCE) e Empresa Brasileira de Pesquisa Agropecuária (EMBRAPA). Assim, foram selecionados cinco tipos de sementes: Cynodon dactylon (grama Bermuda), Andropogon gayanus cv. Planaltina (capim Andropogon), Cenchrus ciliaris L. (capim Buffel), Panicum maximum cv Massai (capim Massai) e Panicum maximum cv Mombaça (capim Mombaça). 
Os principais critérios adotados para escolha dessas espécies foram: alta resistência à seca, crescimento perene, pouca exigência quanto à fertilidade do solo e baixo custo de aquisição (Lauretti, 2003; Pereira, 2006; Veras et al., 2010).

As sementes (aproximadamente 100g de cada) foram lançadas sobre a cobertura da CE e posteriormente cobertas manualmente com uma fina camada (1-2cm) de solo natural disponível no entorno da CE. Esse tipo de plantio trouxe rapidez e a economia, no entanto, a semeadura ocorreu de forma irregular e a emergência desuniforme. $O$ processo de irrigação foi manual e duas vezes ao dia durante a germinação e crescimento inicial com aproximadamente 2,5 litros. $\mathrm{m}^{-2}$ por turno, já que não havia disponibilidade de água superior a essa taxa.

Quanto à fertilidade do solo, duas amostras da camada de cobertura foram coletadas na profundidade de 0 - $20 \mathrm{~cm}$ e analisadas no Laboratório de Solos, do Centro de Ciências Agrárias da Universidade Federal do Ceará. Segundo Bernardo (1995), o Laboratório de Salinidade dos Estados Unidos da América adota quatro categorias para a classificação dos solos afetados por sais: solos normais; solos salinos; solos salino-alcalino ou alcalino-sódico; e solo alcalino ou sódico. Considerando que os solos salinos apresentam Condutividade elétrica superior a 4,0 $\mathrm{dSm}^{-1}$ (resultado dessa pesquisa: 2,26 - 5,42 $\mathrm{dSm}^{-1}$ ) e que os solos sódicos apresentam PST superior a 15\% (resultado dessa pesquisa: 14 - 20\%), o solo da camada de cobertura foi classificado como solos salino-alcalino ou alcalino-sódico.

Como o solo da camada de cobertura teve de baixa a muito baixa permeabilidade, há um aumento no tempo gasto para a água infiltrar e isso induz o processo de degradação da fertilidade do solo, já que ocorre aumento da concentração dos sais na superfície após a evaporação da água. O solo da cobertura apresenta alta saturação de base (96 - 100\%) e isso reduz a concentração de sódio trocável no solo, a expansão e dispersão de argila, já que não há substituição de íons $\mathrm{Ca}^{2+} \mathrm{e}$ $\mathrm{Mg}^{2+}$ por $\mathrm{Na}^{+}$, o que aumenta a atração entre as partículas do solo. Além disso, o solo estudado tem baixo de sodificação (RAS $<10$ ).

Para determinar o fluxo no solo cultivado foi efetuado um corte uniforme em todos os cultivos após 60 dias da germinação a $10 \mathrm{~cm}$ do solo (Carvalho, Freitas e Andrade, 1995; Dantas Neto et al., 2000; Mesquita et al., 2010).

\section{Medição dos Gases na Cobertura e nos Solos Cultivados}

As estimativas das emissões de gases pela camada de cobertura vegetada e não vegetada foram realizadas através de ensaios com placa de fluxo estático em duas campanhas. Nessa modalidade, os gases sofrem recirculação entre o leitor de concentração e o interior da placa através de conexões de borracha, compondo um ciclo fechado. Para tanto, foram confeccionadas cinco placas com chapa de aço em forma de degrau e na parte superior da cada placa foi fixada (com parafuso e fita dupla face $3 \mathrm{M}$ ) uma peça quadrada (de $40 \mathrm{~cm} \times 40 \mathrm{~cm}$ ) de acrílico de $0,5 \mathrm{~cm}$ de espessura; onde dois pequenos orifícios recebiam as conexões de borracha do leitor de gases.

A placa confeccionada seguiu o modelo proposto por Maciel (2003), sendo considerada adequada para estudos in situ pela simples instalação, baixo custo e precisos resultados pontuais. Cada placa possuía uma área útil de $0,16 \mathrm{~m}^{-2}$ e volume de 8 litros.

$\mathrm{O}$ equipamento utilizado para medir a concentração dos gases foi o detector portátil da marca GEM2000 (LANDTEC), que foi alugado. Esse equipamento permite a leitura simultânea das percentagens volumétricas de $\mathrm{CH}_{4}, \mathrm{CO}_{2}$ e $\mathrm{O}_{2}$, além da temperatura interna e da pressão dos gases.

O GEM2000 foi programado para (i) realizar uma leitura (chamada de ciclo) a cada 5 minutos e (ii) lê a concentração dos gases durante 30 segundos sem interrupções. O monitoramento dos gases em cada ensaio de placa durou 180 minutos, tanto no turno da manhã quanto da tarde. Na Figura 1 podem ser observados o GEM2000 conectado a placa instalada na camada de cobertura, a título de exemplo.

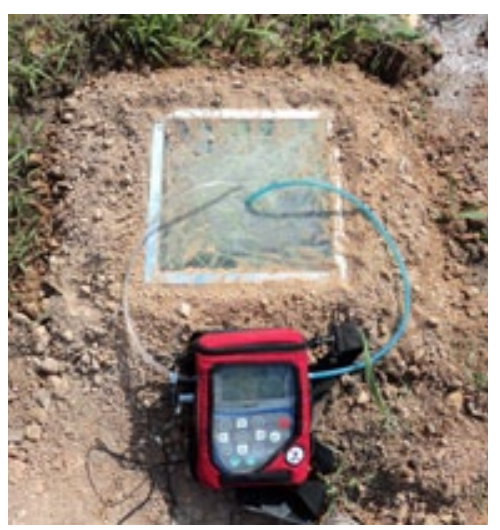

Figura 1 - Vista do GEM2000 conectado a placa na cobertura 
O fluxo do gás foi calculado através de uma equação comum aos estudos sobre a emissão de gases em camadas de cobertura (Park e Shin, 2001; Abichou et al., 2006; Scheutz et al., 2008).

$$
J=\frac{V_{p} \cdot \rho_{g a ́ s}}{A} \cdot \frac{\Delta C}{\Delta t}
$$

Em que: $\mathrm{J}=$ fluxo do gás expresso em $\mathrm{kgm}^{-2} \cdot \mathrm{s}^{-1} ; \mathrm{Vp}=$ volume útil da placa de fluxo $\left(0,008 \mathrm{~m}^{3}\right) ; \mathrm{A}=$ área de solo coberta pela placa $\left(0,16 \mathrm{~m}^{2}\right) ; \rho$ gás = densidade do gás a determinada temperatura $\left(\mathrm{kgm}^{-3}\right) ; \Delta \mathrm{C} / \Delta \mathrm{t}=$ variação da concentração do gás (\%vol.) com o tempo (s). A densidade dos gases $\mathrm{CH}_{4}$ e $\mathrm{CO}_{2}$ foi corrigida em função das leituras de temperatura interna da placa por meio das seguintes expressões:

$$
\begin{aligned}
\rho_{\mathrm{CH} 4}(t) & =\frac{\rho \mathrm{CH}_{4}\left(0^{\circ} \mathrm{C}\right) \cdot 273}{(273+t)} \\
\rho_{\mathrm{CO} 2}(t) & =\frac{\rho C H_{4} \cdot P M_{\mathrm{CO} 2}}{P M_{\mathrm{CH} 4}}
\end{aligned}
$$

Em que: $\rho_{\mathrm{CH} 4}(\mathrm{t})=$ densidade do metano em função da temperatura $(\mathrm{t})$ em ${ }^{\circ} \mathrm{C} ; \rho_{\mathrm{CH} 4}\left(0^{\circ} \mathrm{C}\right)=0,716 \mathrm{kgm}-3 ; \rho_{\mathrm{CO} 2}(\mathrm{t})=$ densidade do dióxido de carbono em função da temperatura (t) em ${ }^{\circ} \mathrm{C} ; \mathrm{PM}_{\mathrm{CH} 4}=$ peso molecular do metano (16), $\mathrm{PM}_{\mathrm{CO} 2}=$ peso molecular do dióxido de carbono (44).

Os resíduos estavam aterrados há seis meses $\left(1^{\mathrm{a}}\right.$ campanha) e há um ano ( $2^{\mathrm{a}}$ campanha).

\section{Resultados e Discussão}

\section{Camada de cobertura ("branco")}

As concentrações dos gases $\mathrm{CH}_{4}$ e $\mathrm{CO}_{2}$ no interior da placa durante as campanhas $\left(1^{\mathrm{a}}\right.$ : de 09 a 13 de janeiro de 2012, $2^{\mathrm{a}}$ : de 06 a 10 de junho de 2012) aumentaram ao longo dos 180 minutos de monitoramento. A Figura 2 mostra o comportamento das concentrações durante o monitoramento.

Os gases emitidos pelo solo da camada de cobertura ("branco") foram compostos, na primeira campanha, em média, por $11,6 \%$ de $\mathrm{CO}_{2}, 6,5 \%$ de $\mathrm{CH}_{4}$, $9,1 \%$ de $\mathrm{O}_{2}$ e $72,7 \%$ de outros gases (identificados desta forma pelo equipamento). Na segunda campanha, houve um aumento na concentração dos dois principais gases de interesse $\left(\mathrm{CO}_{2}\right.$ e $\left.\mathrm{CH}_{4}\right)$ e redução na concentração de $\mathrm{O}_{2}$ e de outros gases (média):

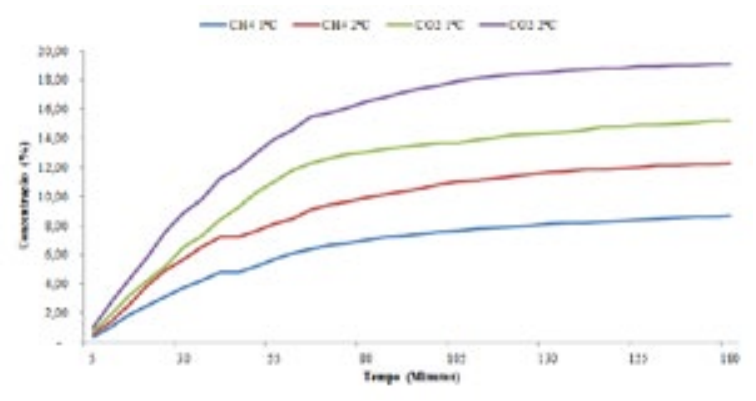

\begin{tabular}{|c|c|c|c|c|c|c|c|c|}
\hline \multicolumn{9}{|c|}{ Dados da semana de monitoramento (\%) } \\
\hline \multirow{2}{*}{ Variável Calculada } & \multicolumn{2}{|c|}{$\mathrm{CH}_{4}$} & \multicolumn{2}{|c|}{$\mathrm{CO}_{2}$} & \multicolumn{2}{|c|}{$\mathrm{O}_{2}$} & OG & OG \\
\hline & $1^{\mathrm{a}} \mathrm{C}$ & $2^{\mathrm{a}} \mathrm{C}$ & $1^{\mathrm{a}} \mathrm{C}$ & $2^{\mathrm{a}} \mathrm{C}$ & $1^{\mathrm{a}} \mathrm{C}$ & $2^{\mathrm{a}} \mathrm{C}$ & $1^{\text {a } C}$ & $2^{\mathrm{a}} \mathrm{C}$ \\
\hline Moda & 7,6 & 13,5 & 12,0 & 17,2 & 9,0 & 6,0 & 70,5 & 65,0 \\
\hline Mínimo & 0,2 & 0,3 & 0,4 & 0,6 & 6,0 & 4,0 & 63,5 & 55,7 \\
\hline Máximo & 10,8 & 14,8 & 19,1 & 23,2 & 13,0 & 10,7 & 88,2 & 89,6 \\
\hline Desvio padrão & 2,6 & 3,6 & 4,6 & 5,5 & 1,5 & 1,5 & 6,0 & 8,0 \\
\hline Aumento da média & 2,8 & 3,3 & - & - & & & & \\
\hline Redução da média & - & - & 1,9 & 4,2 & & & & \\
\hline
\end{tabular}

Figura 2 - Concentração (\%) de $\mathrm{CH}_{4}$ e $\mathrm{CO}_{2}$ na placa (cobertura da CE, duas campanhas)

$\mathrm{C}=$ Campanha, $\mathrm{OG}=$ Outros Gases

Tabela 2 - Resultados das concentrações dos gases na camada de cobertura (duas campanhas) 
$14,9 \%$ de $\mathrm{CO}_{2}, 9,4 \%$ de $\mathrm{CH}_{4}, 7,2 \%$ de $\mathrm{O}_{2}$ e $68,5 \%$ de outros gases. Outras variáveis calculadas estão na Tabela 2.

Como se observa na Tabela 2, da primeira para a segunda campanha de monitoramento a concentração de $\mathrm{CH}_{4}$ que mais se repetiu no interior da placa (Moda) foi $7,6\left(1^{\mathrm{a}} \mathrm{C}\right)$ e $13,5 \%\left(2^{\mathrm{a}} \mathrm{C}\right)$, para o $\mathrm{CO}_{2}$ foi 12,0 e $17,2 \%$ e para $\mathrm{O}_{2}$ foi 9,0 e $6,0 \%$. Observou-se ainda que a menor concentração de $\mathrm{CH}_{4}$ foi 0,2 $\left(1^{\mathrm{a}} \mathrm{C}\right)$ e $0,3 \%\left(2^{\mathrm{a}} \mathrm{C}\right)$ e a maior 10,8 e $14,8 \%$ entre as campanhas. Para o $\mathrm{CO}_{2}$ (menores valores: 0,4 e 0,6\%; maiores valores: 19,1 e $23,2 \%$ ). Para o $\mathrm{O}_{2}$ (menores valores: 6,0 e 4,0\%; maiores valores: 13,0 e 10,7\%). Observou-se um aumento na dispersão dos dados referentes às concentrações de todos os gases de uma campanha para outra, exceto para o oxigênio (mesmo desvio padrão). Os fluxos estão consolidados na Tabela 3, mas nas duas condições tem-se uma célula de resíduos na fase ácida de digestão, entendida como a etapa onde há conversão microbiológica do material orgânico complexo em compostos com baixa massa molecular, como o ácido acético. Nessa fase, o dióxido de carbono é o principal gás gerado e também serão produzidas quantidades menores de hidrogênio.

Os resultados das cinco coletas das variáveis físico-químicas do chorume (pH: 5,63 a 6,56; Turbidez: 47,5 a 187,6 uT; Cor Aparente: 2540 a 6001 uH; Ferro: 2,01 a 5,02 $\mathrm{mgL}^{-1}$; Sólidos Dissolvidos Totais: 14280 a $40111 \mathrm{mgL}^{-1}$; Alcalinidade: 28,3 a 141,3 $\mathrm{mgL}^{-1}$; Condutividade: 21000 a $43321 \mu \mathrm{Scm}$ 1; Amônia: 8,58 a 19,1 $\mathrm{mgL}^{-1}$; Nitrito: 0,81 a 1,01 $\mathrm{mgL}^{-1}$; Nitrato: 3,30 a $4,78 \mathrm{mgL}^{-1}$; Fósforo total: 8,62 a $12,2 \mathrm{mgL}^{-1}$; DQO: 4858 a $7269 \mathrm{mgL}^{-1}$ ) reafirmam a fase ácida de digestão.

A ampla faixa de variação do fluxo indica que existem vários fatores que interferem na emissão desses gases: (i) características geotécnicas do solo, (ii) qualidade e espessura da camada de cobertura, (iii) pressões de gases no contato solo-resíduo, (iv) idade dos resíduos, (v) condições climáticas da região etc.

Os resultados dos fluxos medidos na cobertura da CE durante as duas campanhas estão dentro dos intervalos constantes na literatura, como se observa na Tabela 4.

Como se observa, cada área pesquisada pelos autores listados na Tabela 4 apresenta uma particular capacidade de permitir ou reter o fluxo dos gases, assim como observado nessa pesquisa.

As características geotécnicas do solo empregado na cobertura de um aterro permitem a criação de múltiplos cenários de emissão ou retenção, ou seja, se o solo estiver mais compactado numa determinada área em relação à outra, deverá existir um menor número de espaços vazios em seu interior com consequente menor fuga dos gases.

Se os materiais de cobertura forem escolhidos com maior rigor (solos argilosos são melhores que solos arenosos devido a coesão entre as partículas) e a espessura da camada de cobertura atender a recomendações das normas (maior que $60 \mathrm{~cm}$ ) espera-se que ao aterro retenha um volume maior de gases, além de facilitar a movimentação de veículos sobre a massa de resíduos coberta e aumentar a estabilidade da área, evitando desmoronamentos e acidentes.

As pressões dos gases no contato solo-resíduo tendem a aumentar com a profundidade do aterro e a tendência natural desses gases é escapar para a atmosfera, seja pela cobertura, seja pelas laterais do aterro; assim algumas áreas podem apresentar

\begin{tabular}{|c|c|c|c|c|c|c|}
\hline \multirow{2}{*}{\multicolumn{3}{|c|}{ Variável Calculada }} & $\mathrm{CH}_{4}$ & & $\mathrm{CO}_{2}$ & \\
\hline & & & $1^{\mathrm{a}} \mathrm{C}$ & $2^{a} C$ & $1^{\mathrm{a}} \mathrm{C}$ & $2^{a} \mathrm{C}$ \\
\hline Média & \multirow{3}{*}{ mássico } & \multirow{3}{*}{$\mathrm{gm}^{2} \cdot \mathrm{s}^{-1}$} & $2,5 \times$ & $3,6 \times$ & $1,2 \times 10^{-2}$ & $1,5 \times 10^{-2}$ \\
\hline Mínimo & & & 0,0 & 0,0 & 0,0 & 0,0 \\
\hline Máximo & & & $1,3 \times 10^{-2}$ & $2,9 \times 10^{-2}$ & $6,9 \times 10^{-2}$ & $8,6 \times 10^{-2}$ \\
\hline Média & \multirow{2}{*}{ volumétrico } & \multirow{2}{*}{$m^{3} m^{-2} \cdot s^{-1}$} & $4,0 \times 10^{-6}$ & $5,7 \times 10^{-6}$ & $7,0 \times 10^{-6}$ & $8,8 \times 10^{-6}$ \\
\hline Máximo & & & $2,0 \times 10^{-5}$ & $4,6 \times 10^{-5}$ & $4,0 \times 10^{-5}$ & $5,0 \times 10^{-5}$ \\
\hline
\end{tabular}

Tabela 3 - Fluxos mássicos e volumétricos dos gases pela cobertura (duas campanhas) 


\begin{tabular}{|c|c|c|}
\hline \multirow{2}{*}{ Autor(es)/ano } & \multicolumn{2}{|c|}{ Emissão superficial } \\
\hline & $\mathrm{CH}_{4}$ & $\mathrm{CO}_{2}$ \\
\hline Park e Shin (2001) & $\begin{array}{c}0,0055-2,4137 \mathrm{~m}^{3} \mathrm{~m}^{-2} \cdot \mathrm{h}^{-1} \\
\left(1,5 \times 10^{-6}-6,7 \times 10^{-4} \mathrm{~m}^{3} \mathrm{~m}^{-2} \cdot \mathrm{h}^{-1}\right)^{*}\end{array}$ & $\begin{array}{c}0,0121-2,639 \mathrm{~m}^{3} \mathrm{~m}^{-2} \cdot \mathrm{h}^{-1} \\
\left(3,4 \times 10^{-6}-7,3 \times 10^{-4} \mathrm{~m}^{3} \mathrm{~m}^{-2} \cdot \mathrm{h}^{-1}\right)^{*}\end{array}$ \\
\hline Marion e Peter (1998) & $\begin{array}{c}0,1-0,4 \mathrm{~m}^{3} \mathrm{~m}^{-2} \cdot \mathrm{h}^{-1} \\
\left(2,8 \times 10^{-5}-1,1 \times 10^{-4} \mathrm{~m}^{3} \mathrm{~m}^{-2} \cdot \mathrm{h}^{-1}\right)^{*}\end{array}$ & - \\
\hline Hedge, Chan e Yang (2003) & $\begin{array}{c}0,99-157,56 \mathrm{mgm}^{-2} \cdot \mathrm{h}^{-1} \\
\left(2,8 \times 10^{-7}-4,4 \times 10^{-5} \mathrm{gm}^{-2} \cdot \mathrm{s}^{-1}\right)^{*}\end{array}$ & $\begin{array}{c}48,46-99,21 \mathrm{mgm}^{-2} \cdot \mathrm{h}^{-1} \\
\left(1,3 \times 10^{-5}-2,8 \times 10^{-5} \mathrm{gm}^{-2} \cdot \mathrm{s}^{-1}\right)^{*}\end{array}$ \\
\hline Laurila et al. (2006) & $\begin{array}{c}0,5-74 \mathrm{~m}^{3} \mathrm{ha}^{-1} \cdot \mathrm{h}^{-1} \\
\left(1,4 \times 10-8-2,1 \times 10^{-6} \mathrm{~m}^{3} \mathrm{~m}^{-2} \cdot \mathrm{s}^{-1}\right)^{*}\end{array}$ & - \\
\hline Milke, Holman e Khire (2006) & $\begin{array}{c}0,005-1,49 \mathrm{gm}^{-2} \cdot \mathrm{min}^{-1} \\
\left(8,3 \times 10^{-5}-2,5 \times 10^{-2} \mathrm{gm}^{2} \cdot \mathrm{s}^{-1}\right)^{*}\end{array}$ & - \\
\hline Stern et al. (2007) & $\begin{array}{c}18,1 \mathrm{gm}^{-2} \cdot \mathrm{h}^{-1} \\
\left(5,0 \times \mathrm{gm}^{-2} \cdot \mathrm{s}^{-1}\right)^{*}\end{array}$ & - \\
\hline Scheutz et al. (2008) & $\begin{array}{c}29 \mathrm{gm}^{-2} \cdot \mathrm{d}^{-1} \\
\left(3,4 \times 10^{-4} \mathrm{gm}^{-2} \cdot \mathrm{s}^{-1}\right)^{*}\end{array}$ & - \\
\hline Jha et al. (2008) & $\begin{array}{c}1,0-23,5 \mathrm{mgm}^{-2} \cdot \mathrm{h}^{-1} \\
\left(2,8 \times 10^{-7}-6,5 \times 10^{-6} \mathrm{gm}^{-2} \cdot \mathrm{s}^{-1}\right)^{*}\end{array}$ & $\begin{array}{c}39,0-906 \mathrm{mgm}^{-2} \cdot \mathrm{h}^{-1} \\
\left(1,1 \times 10^{-5}-2,5 \times 10^{-4} \mathrm{gm}^{-2} \cdot \mathrm{s}^{-1}\right)^{*}\end{array}$ \\
\hline Georgaki et al. (2008) & $\begin{array}{c}17 \mathrm{gm}^{-2} \cdot \mathrm{h}^{-1} \\
\left(4,7 \times 10^{-3} \mathrm{gm}^{-2} \cdot \mathrm{s}^{-1}\right)^{*}\end{array}$ & $\begin{array}{c}33 \mathrm{gm}^{-2} \cdot \mathrm{h}^{-1} \\
\left(9,2 \times 10^{-3} \mathrm{gm}^{-2} \cdot \mathrm{s}^{-1}\right)^{*}\end{array}$ \\
\hline Johnsson (2010) & $\begin{array}{c}0,0004-0,06 \mathrm{gm}^{-2} \cdot \mathrm{h}^{-1} \\
\left(1,1 \times 10^{-7}-1,7 \times 10^{-5} \mathrm{gm}^{-2} \cdot \mathrm{s}^{-1}\right)^{*}\end{array}$ & $\begin{array}{c}1,26-4,45 \mathrm{gm}^{-2} \cdot \mathrm{h}^{-1} \\
\left(3,5 \times 10^{-4}-1,2 \times 10^{-3} \mathrm{gm}^{-2} \cdot \mathrm{s}^{-1}\right)^{*}\end{array}$ \\
\hline Capaccioni et al. (2011) & $\begin{array}{c}3,8 \mathrm{gm}^{-2} \cdot \mathrm{d}^{-1} \\
\left(4,4 \times 10^{-5} \mathrm{gm}^{-2} \cdot \mathrm{s}^{-1}\right)^{*}\end{array}$ & $\begin{array}{c}13,1 \mathrm{gm}^{-2} \cdot \mathrm{d}^{-1} \\
\left(1,5 \times 10^{-4} \mathrm{gm}^{-2} \cdot \mathrm{s}^{-1}\right)^{*}\end{array}$ \\
\hline $\begin{array}{l}\text { Nava-Martinez, Garcia-Flores e Waki- } \\
\text { da (2011) }\end{array}$ & $\begin{array}{c}0,17-2441,81 \mathrm{gm}^{-2} \cdot \mathrm{h}^{-1} \\
\left(4,7 \times 10^{-5}-6,8 \times 10^{-1} \mathrm{gm}^{-2} \cdot \mathrm{s}^{-1}\right)^{*}\end{array}$ & - \\
\hline Maciel (2003) & $1,2-4,2 \times 10^{-3} \mathrm{gm}^{-2} \cdot \mathrm{s}^{-1}$ & - \\
\hline Fernandes (2009) & $\begin{array}{c}23,24-337,67 \mathrm{gm}^{-2} \cdot \mathrm{d}^{-1} \\
\left(2,7 \times 10^{-4}-3,9 \times 10^{-3} \mathrm{gm}^{-2} \cdot \mathrm{s}^{-1}\right)^{*}\end{array}$ & $\begin{array}{c}29,09 \text { e } 233,24 \mathrm{gm}^{-2} \cdot \mathrm{d}^{-1} \\
\left(3,4 \times 10^{-4}-2,7 \times 10^{-3} \mathrm{gm}^{-2} \cdot \mathrm{s}^{-1}\right)^{*}\end{array}$ \\
\hline Berto Neto (2009) & $\begin{array}{c}5,66-148,20 \mathrm{gm}^{-2} \cdot \mathrm{d}^{-1} \\
\left(6,6 \times 10^{-5}-1,7 \times 10^{-3} \mathrm{gm}^{-2} \cdot \mathrm{s}^{-1}\right)^{*}\end{array}$ & $\begin{array}{c}17,78-223,04 \mathrm{gm}^{-2} \cdot \mathrm{d}^{-1} \\
\left(2,1 \times 10^{-4}-2,6 \times 10^{-3} \mathrm{gm}^{-2} \cdot \mathrm{s}^{-1}\right)^{*}\end{array}$ \\
\hline Mariano e Jucá (2010) & $\begin{array}{l}7-146 \mathrm{kgm}^{-2} \cdot \mathrm{ano}^{-1} \\
\left(2,2 \times 10^{-4} \mathrm{gm}^{-2} \cdot \mathrm{s}^{-1}\right)^{*}\end{array}$ & - \\
\hline Lopes et al. (2010) & $\begin{array}{c}35,20-151,95 \mathrm{gm}^{-2} \cdot \mathrm{d}^{-1} \\
\left(4,1 \times 10^{-4}-1,8 \times 10^{-3} \mathrm{gm}^{-2} \cdot \mathrm{s}^{-1}\right)^{*}\end{array}$ & $\begin{array}{c}58,07-644,74 \mathrm{gm}^{-2} \cdot \mathrm{d}^{-1} \\
\left(6,7 \times 10^{-4}-7,5 \times 10^{-3} \mathrm{gm}^{-2} \cdot \mathrm{s}^{-1}\right)^{*}\end{array}$ \\
\hline Dados encontrados (médias) & $\begin{array}{c}2,5 \times 10^{-3} \mathrm{gm}^{-2} \cdot \mathrm{s}^{-1} \text { ou } \\
4,0 \times 10^{-6} \mathrm{~m}^{3} \mathrm{~m}^{-2} \cdot \mathrm{s}^{-1}\left(1^{\mathrm{a}} \mathrm{C}\right) \\
3,6 \times 10^{-3} \mathrm{gm}^{-2} \cdot \mathrm{s}^{-1} \text { ou } \\
5,7 \times 10^{-6} \mathrm{~m}^{3} \mathrm{~m}^{-2} \cdot \mathrm{s}^{-1}\left(2^{\mathrm{a}} \mathrm{C}\right)\end{array}$ & $\begin{array}{c}1,2 \times 10^{-2} \mathrm{gm}^{-2} \cdot \mathrm{s}^{-1} \text { ou } \\
7,0 \times 10^{-6} \mathrm{~m}^{3} \mathrm{~m}^{-2} \cdot \mathrm{s}^{-1}\left(1^{\mathrm{a}} \mathrm{C}\right) \\
1,5 \times 10^{-2} \mathrm{gm}^{-2} \cdot \mathrm{s}^{-1} \text { ou } \\
8,8 \times 10^{-6} \mathrm{~m}^{3} \mathrm{~m}^{-2} \cdot \mathrm{s}^{-1}\left(2^{\mathrm{a}} \mathrm{C}\right)\end{array}$ \\
\hline
\end{tabular}

* Unidade convertida para a utilizada neste trabalho, facilitando a comparação. C C = Campanha 


\begin{tabular}{|c|c|c|c|c|c|c|c|}
\hline \multirow{2}{*}{ Turno } & \multirow{2}{*}{\multicolumn{3}{|c|}{ Variável Calculada }} & \multicolumn{2}{|c|}{$\mathrm{CH}_{4}$} & \multicolumn{2}{|c|}{$\mathrm{CO} 2$} \\
\hline & & & & $1^{a} \mathrm{C}$ & $2^{a} C$ & $1^{\mathrm{a}} \mathrm{C}$ & $2^{a} \mathrm{C}$ \\
\hline \multirow{5}{*}{ Manhã } & Média & \multirow{3}{*}{ mássico } & \multirow{3}{*}{$\mathrm{gm}^{-2} \cdot \mathrm{s}-1$} & $2,5 \times 10^{-3}$ & $3,5 \times 10^{-3}$ & $1,1 \times 10^{-2}$ & $1,5 \times 10^{-2}$ \\
\hline & Mínimo & & & 0,0 & 0,0 & 0,0 & 0,0 \\
\hline & Máximo & & & $1,3 \times 10^{-2}$ & $1,8 \times 10^{-2}$ & $6,9 \times 10^{-2}$ & $8,6 \times 10^{-2}$ \\
\hline & Média & \multirow{2}{*}{ volumétrico } & \multirow{2}{*}{$\mathrm{m} 3 \mathrm{~m}^{-2} \cdot \mathrm{s}-1$} & $3,9 \times 10^{-6}$ & $5,6 \times 10^{-6}$ & $6,5 \times 10^{-6}$ & $8,5 \times 10^{-6}$ \\
\hline & Máximo & & & $2,0 \times 10^{-5}$ & $2,9 \times 10^{-5}$ & $4,0 \times 10^{-5}$ & $5,0 \times 10^{-5}$ \\
\hline \multirow{5}{*}{ Tarde } & Média & \multirow{3}{*}{ mássico } & \multirow{3}{*}{$\mathrm{gm}^{-2} \cdot \mathrm{s}-1$} & $2,6 \times 10^{-3}$ & $3,6 \times 10^{-3}$ & $1,3 \times 10^{-2}$ & $1,6 \times 10^{-2}$ \\
\hline & Mínimo & & & 0,0 & 0,0 & 0,0 & 0,0 \\
\hline & Máximo & & & $1,2 \times 10^{-2}$ & $2,9 \times 10^{-2}$ & $6,6 \times 10^{-2}$ & $8,1 \times 10^{-2}$ \\
\hline & Média & \multirow{2}{*}{ volumétrico } & \multirow{2}{*}{$m 3 m^{-2} \cdot s-1$} & $4,1 \times 10^{-6}$ & $5,7 \times 10^{-6}$ & $7,4 \times 10^{-6}$ & $9,0 \times 10^{-6}$ \\
\hline & Máximo & & & $2,0 \times 10^{-5}$ & $4,6 \times 10^{-5}$ & $3,8 \times 10^{-5}$ & $4,7 \times 10^{-5}$ \\
\hline
\end{tabular}

Tabela 5 - Fluxos mássico e volumétrico na cobertura (duas campanhas por turno)

maior ou menor fluxo.

A idade dos resíduos também deve ser considerada em estudos sobre gases: aterros "novos" tendem a emitir um maior volume de gás quando comparados a "aterros antigos" especialmente em função da degradação dos resíduos classificados como facilmente degradáveis, sendo que a recirculação do chorume sobre o platô do aterro potencializa a produção de gás nas duas situações.

Da mesma forma, as condições climáticas da região influem no volume e na qualidade do gás emitido pelo aterro já que as águas pluviais que caem sobre a área e a porção que infiltra na massa de resíduos distribui umidade, nutrientes e microrganismos, aumentando as reações de degradação e potencializando a geração de gás. Da mesma forma, baixa umidade implica em um processo de digestão mais lento com menor geração de gás.

Os resultados dos fluxos medidos na cobertura da CE durante as duas campanhas por turno estão consolidados na Tabela 5, da qual se observou que os maiores valores aconteceram pela tarde, podendo o aumento natural da temperatura na massa de lixo decorrente das reações de biodegradação, bem como o aumento da temperatura externa ao aterro (turno mais quente do dia) terem influenciado, já que reduz-se a saturação do solo em função da evaporação superficial da água e aumenta-se o número de espaços vazios, permitindo um maior fluxo.

\section{Camada de cobertura cultivada}

Os dados alcançados durante as leituras das emissões pelo solo cultivado com os capins Mombaça, Massai, Buffel, Andropogon e grama Bermuda, nas duas campanhas $\left(1^{\mathrm{a}}\right.$ : de 09 a 13 de janeiro de 2012; $2^{\text {a. }}$ de 13 a 17 de agosto de 2012) permitiram observar que houve crescimento na concentração (\%) do $\mathrm{CH}_{4}$ e $\mathrm{CO}_{2}$ no interior da placa ao longo dos 180 minutos de monitoramento, mas abaixo do encontrado no monitoramento da área considerada como "branco". As Figuras 3 a 10 mostram o comportamento comparativo dessas diferenças nas concentrações dos gases no interior da placa ("branco" $\mathrm{x}$ cultivo).

Os gases emitidos pelo solo cultivado com capim Mombaça foram compostos, na primeira campanha, em média, por $7,0 \%$ de $\mathrm{CO}_{2}, 3,9 \%$ de $\mathrm{CH}_{4}, 5,5 \%$ de $\mathrm{O}_{2}$ e 83,6\% de outros gases (identificados desta forma pelo equipamento). Na segunda campanha, houve um aumento na concentração dos dois prin-

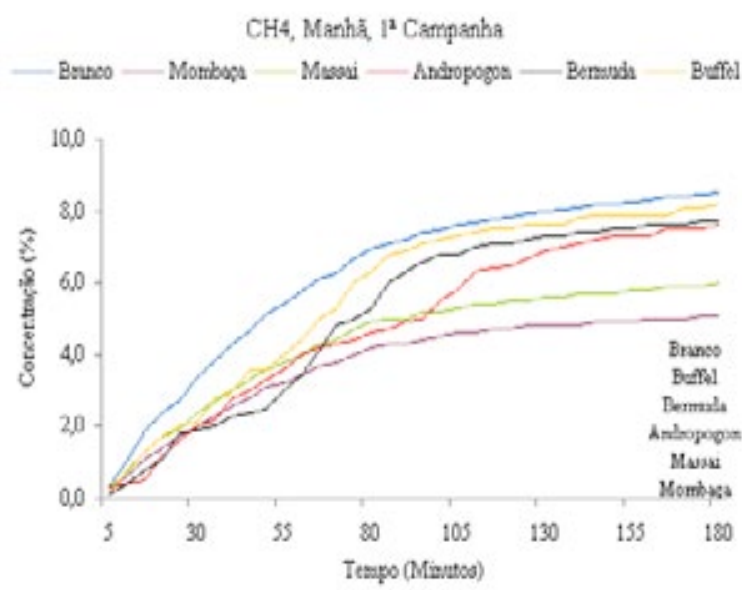

Figura 3 - Concentração (\%) de $\mathrm{CH}_{4}$ no "branco" e nos cultivos (1 ${ }^{\text {a }}$ campanha, manhã) 


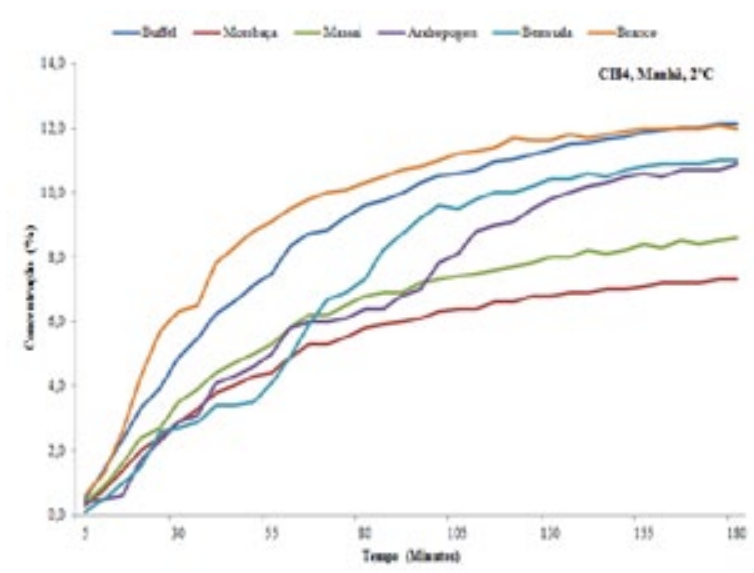

Figura 4 - Concentração (\%) de $\mathrm{CH}_{4}$ no "branco" e nos cultivos (2a campanha, manhã)

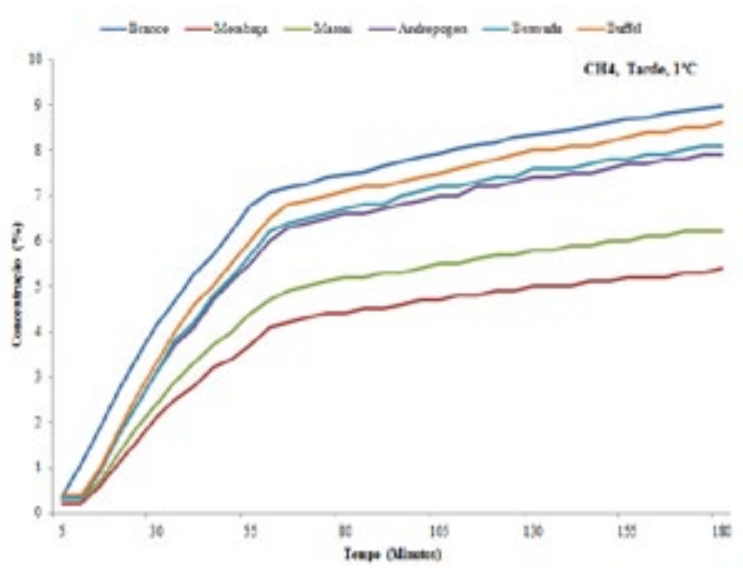

Figura 5 - Concentração (\%) de $\mathrm{CH}_{4}$ no "branco" e nos cultivos ( $1^{\text {a }}$ campanha, tarde)

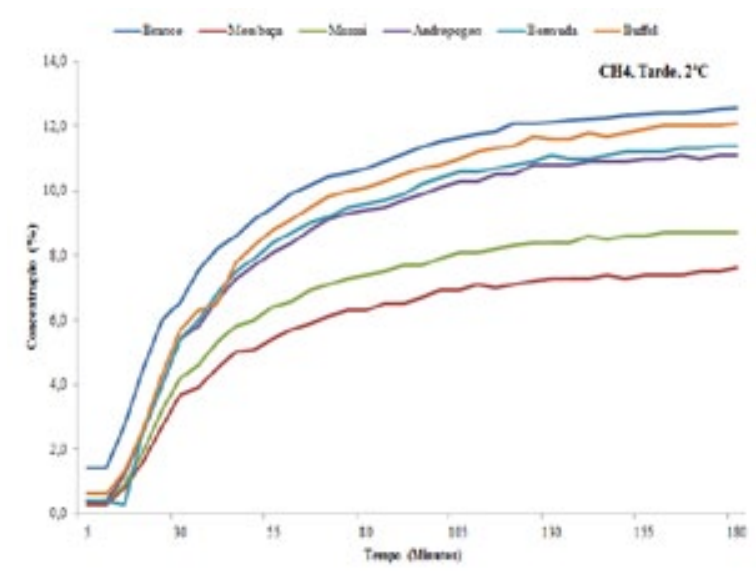

Figura 6 - Concentração (\%) de $\mathrm{CH}_{4}$ no "branco" e nos cultivos (2a campanha, tarde)

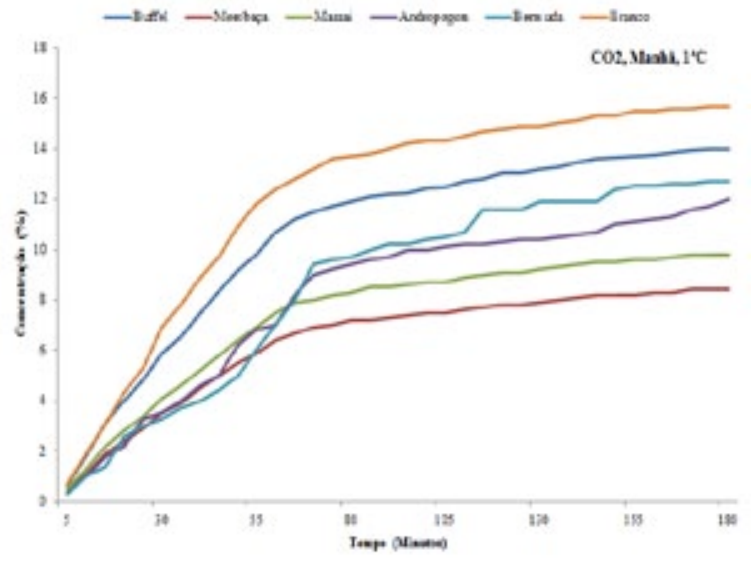

Figura 7 - Concentração (\%) de CO2 no "branco" e nos cultivos (1 ${ }^{\text {a }}$ campanha, manhã)

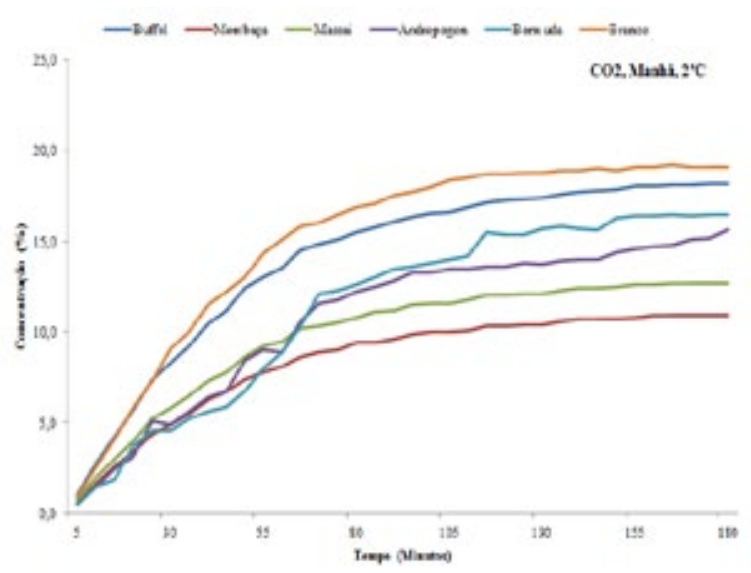

Figura 8 - Concentração (\%) de CO2 no "branco" e nos cultivos (2a campanha, manhã)

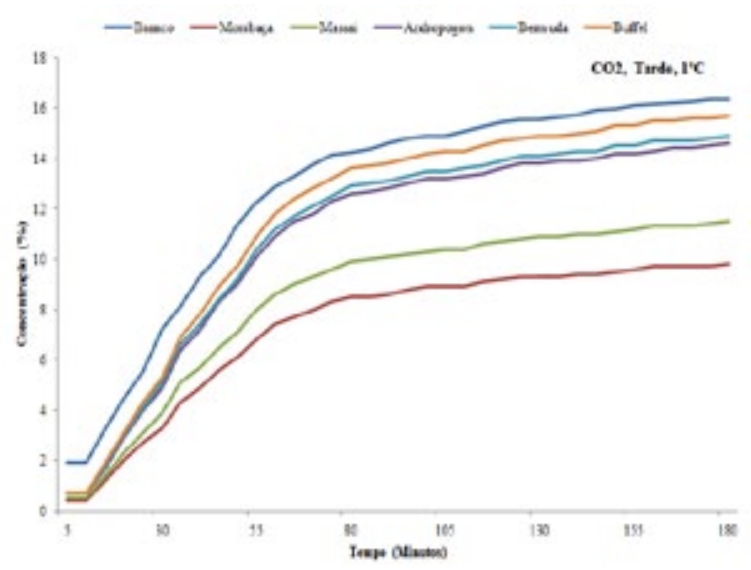

Figura 9 - Concentração (\%) de CO2 no "branco" e nos cultivos (1 ${ }^{\text {a }}$ campanha, tarde) 


\section{Artigo Técnico}

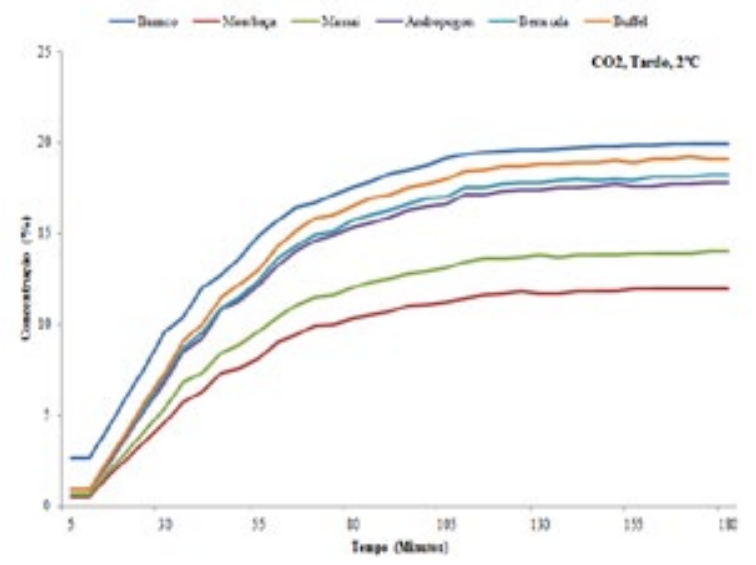

Figura 10 - Concentração (\%) de CO2 no "branco" e nos cultivos (2a campanha, tarde) cipais gases de interesse $\left(\mathrm{CO}_{2}\right.$ e $\left.\mathrm{CH}_{4}\right)$ e redução na concentração de $\mathrm{O}_{2}$ e de outros gases (média): 8,9\% de $\mathrm{CO}_{2}, 5,6 \%$ de $\mathrm{CH}_{4}, 4,3 \%$ de $\mathrm{O}_{2}$ e $78,7 \%$ de outros gases. Outras variáveis calculadas estão na Tabela 6.

Como se observa na Tabela 6, da primeira para a segunda campanha de monitoramento a concentração de $\mathrm{CH}_{4}$ que mais se repetiu no interior da placa (Moda) foi 4,8 $\left(1^{\mathrm{a}} \mathrm{C}\right)$ e $7,2 \%\left(2^{\mathrm{a}} \mathrm{C}\right)$, para o $\mathrm{CO}_{2}$ foi 9,7 e $11,9 \%$ e para $\mathrm{O}_{2}$ foi 5,7 e $5,3 \%$. Observou-se ainda que a menor concentração de $\mathrm{CH}_{4}$ foi $0,2\left(1^{\mathrm{a}} \mathrm{C}\right)$ e $0,3 \%\left(2^{\mathrm{a}} \mathrm{C}\right)$ e a maior 5,4 e $7,6 \%$ entre as campanhas. Para o $\mathrm{CO}_{2}$ (menores valores: 0,4 e 0,5\%; maiores valores: 9,8 e 11,9\%). Para o $\mathrm{O}_{2}$ (menores valores: 4,1 e 2,9\%; maiores valores: 7,2 e $6,1 \%)$.

Observou-se um aumento na dispersão dos

\begin{tabular}{|c|c|c|c|c|c|c|c|c|}
\hline \multicolumn{9}{|c|}{ Dados da semana de monitoramento (\%) } \\
\hline \multirow{2}{*}{ Variável Calculada } & \multicolumn{2}{|c|}{$\mathrm{CH}_{4}$} & \multicolumn{2}{|c|}{$\mathrm{CO}_{2}$} & \multicolumn{2}{|c|}{$\mathrm{O}_{2}$} & \multirow{2}{*}{$\begin{array}{c}\mathrm{OG} \\
1^{a} \mathrm{C}\end{array}$} & \multirow{2}{*}{$\frac{\text { OG }}{2^{a} \mathrm{C}}$} \\
\hline & $1^{a} \mathrm{C}$ & $2^{a} \mathrm{C}$ & $1^{a} \mathrm{C}$ & $2^{a} \mathrm{C}$ & $1^{a} \mathrm{C}$ & $2^{a} \mathrm{C}$ & & \\
\hline Moda & 4,8 & 7,2 & 9,7 & 11,9 & 5,7 & 5,3 & 82,4 & 76,7 \\
\hline Mínimo & 0,2 & 0,3 & 0,4 & 0,5 & 4,1 & 2,9 & 80,5 & 72,9 \\
\hline Máximo & 5,4 & 7,6 & 9,8 & 11,9 & 7,2 & 6,1 & 92,4 & 93,9 \\
\hline Desvio padrão & 1,4 & 2,0 & 2,6 & 3,1 & 0,9 & 0,8 & 3,3 & 5,6 \\
\hline Aumento da média & \multicolumn{2}{|c|}{1,7} & \multicolumn{2}{|c|}{2,0} & & \\
\hline Redução da média & \multicolumn{2}{|c|}{ - } & \multicolumn{2}{|c|}{ - } & \multicolumn{2}{|c|}{1,1} & \multicolumn{2}{|c|}{4,9} \\
\hline
\end{tabular}

Tabela 6 - Concentrações dos gases (camada com capim Mombaça, duas campanhas)

\begin{tabular}{|c|c|c|c|c|}
\hline \multirow{3}{*}{ Variável Calculada } & \multicolumn{2}{|c|}{$\mathrm{CH}_{4}$} & \multicolumn{2}{|c|}{$\mathrm{CO} 2$} \\
\hline & \multicolumn{4}{|c|}{$\%$} \\
\hline & $1^{a} \mathrm{C}$ & $2^{a} \mathrm{C}$ & $1^{a} \mathrm{C}$ & $2^{a} \mathrm{C}$ \\
\hline Média & 2,6 & 3,8 & 4,6 & 6,0 \\
\hline Mínimo & 0,2 & 0,2 & 0,3 & 0,4 \\
\hline Máximo & 3,6 & 5,0 & 6,6 & 8,0 \\
\hline
\end{tabular}

Tabela 7 - Retenção dos gases (camada com capim Mombaça, duas campanhas)

\begin{tabular}{|c|c|c|c|c|c|c|}
\hline \multirow{2}{*}{\multicolumn{3}{|c|}{ Variável Calculada }} & \multicolumn{2}{|c|}{$\mathrm{CH}_{4}$} & \multicolumn{2}{|c|}{$\mathrm{CO}_{2}$} \\
\hline & & & $1^{a} C$ & $2^{a} C$ & $1^{a} \mathrm{C}$ & $2^{a} \mathrm{C}$ \\
\hline Média & \multirow{3}{*}{ mássico } & \multirow{3}{*}{$\mathrm{gm}^{-2} \cdot \mathrm{s}^{-1}$} & $1,5 \times 10^{-3}$ & $2,2 \times 10^{-3}$ & $7,3 \times 10^{-3}$ & $9,1 \times 10^{-3}$ \\
\hline Mínimo & & & 0,0 & 0,0 & 0,0 & 0,0 \\
\hline Máximo & & & $5,2 \times 10^{-3}$ & $1,1 \times 10^{-2}$ & $2,9 \times 10^{-2}$ & $3,3 \times 10^{-2}$ \\
\hline Média & \multirow{2}{*}{ volumétrico } & \multirow{2}{*}{$\mathrm{m} 3 \mathrm{~m}^{-2} \cdot \mathrm{s}^{-1}$} & $3,3 \times 10^{-6}$ & $4,7 \times 10^{-6}$ & $5,7 \times 10^{-6}$ & $7,2 \times 10^{-6}$ \\
\hline Máximo & & & $1,3 \times 10^{-5}$ & $2,8 \times 10^{-5}$ & $2,7 \times 10^{-5}$ & $3,2 \times 10^{-5}$ \\
\hline
\end{tabular}

Tabela 8 - Fluxos mássicos e volumétricos (camada com capim Mombaça, duas campanhas) 
dados referentes às concentrações de todos os gases de uma campanha para outra, exceto para o oxigênio. Observou-se retenção dos dois gases de interesse pela camada de cobertura cultivada com capim Mombaça nas duas campanhas (medida pela diferença entre a concentração no dreno e a concentração na camada), como apresenta a Tabela 7. Já os fluxos estão consolidados na Tabela 8.

Os gases emitidos pelo solo cultivado com capim Massai foram compostos, na primeira campanha, em média, por $8,1 \%$ de $\mathrm{CO}_{2}, 4,6 \%$ de $\mathrm{CH}_{4}$, $6,4 \%$ de $\mathrm{O}_{2}$ e $80,9 \%$ de outros gases (identifica- dos desta forma pelo equipamento). Na segunda campanha, houve um aumento na concentração dos dois principais gases de interesse $\left(\mathrm{CO}_{2}\right.$ e $\left.\mathrm{CH}_{4}\right)$ e redução na concentração de $\mathrm{O}_{2}$ e de outros gases (média): 10,4\% de $\mathrm{CO}_{2}, 6,6 \%$ de $\mathrm{CH}_{4}, 5,1 \%$ de $\mathrm{O}_{2}$ e $84,9 \%$ de outros gases. Outras variáveis calculadas estão na Tabela 9.

Como se observa na Tabela 9, da primeira para a segunda campanha de monitoramento a concentração de $\mathrm{CH}_{4}$ que mais se repetiu no interior da placa (Moda) foi 5,7 $\left(1^{\mathrm{a}} \mathrm{C}\right)$ e $8,7 \%\left(2^{\mathrm{a}} \mathrm{C}\right)$, para o $\mathrm{CO}_{2}$ foi 9,6 e $12,7 \%$ e para $\mathrm{O}_{2}$ foi 6,6 e $6,0 \%$. Observou-se ainda que a menor concentração

\begin{tabular}{|c|c|c|c|c|c|c|c|c|}
\hline \multicolumn{9}{|c|}{ Dados da semana de monitoramento (\%) } \\
\hline \multirow{2}{*}{ Variável Calculada } & \multicolumn{2}{|c|}{$\mathrm{CH}_{4}$} & \multicolumn{2}{|c|}{$\mathrm{CO}_{2}$} & \multicolumn{2}{|c|}{$\mathrm{O}_{2}$} & \multirow{2}{*}{$\frac{\mathrm{OG}}{1^{a} \mathrm{C}}$} & \multirow{2}{*}{$\frac{\mathrm{OG}}{2^{a} \mathrm{C}}$} \\
\hline & $1^{a} \mathrm{C}$ & $2^{a} \mathrm{C}$ & $1^{a} \mathrm{C}$ & $2^{a} \mathrm{C}$ & $1^{a} \mathrm{C}$ & $2^{a} \mathrm{C}$ & & \\
\hline Moda & 5,7 & 8,7 & 9,6 & 12,7 & 6,6 & 6,0 & 79,8 & 70,4 \\
\hline Mínimo & 0,3 & 0,4 & 0,5 & 0,6 & 4,8 & 3,4 & 77,3 & 70,0 \\
\hline Máximo & 6,3 & 8,8 & 11,5 & 14,0 & 8,4 & 7,1 & 91,1 & 92,5 \\
\hline Desvio padrão & 1,6 & 2,3 & 3,0 & 3,6 & 1,0 & 1,0 & 3,8 & 6,1 \\
\hline Aumento da média & \multicolumn{2}{|c|}{2,0} & \multicolumn{2}{|c|}{2,3} & \multicolumn{2}{|c|}{ - } & \\
\hline Redução da média & \multicolumn{2}{|c|}{ - } & & \multicolumn{2}{|c|}{1,3} & \multicolumn{2}{|c|}{4,6} \\
\hline
\end{tabular}

Tabela 9 - Concentrações dos gases (camada com capim Massai, duas campanhas)

\begin{tabular}{|c|c|c|c|c|}
\hline \multirow{3}{*}{ Variável Calculada } & \multicolumn{2}{|c|}{$\mathrm{CH}_{4}$} & \multicolumn{2}{|c|}{$\mathrm{CO} 2$} \\
\hline & \multicolumn{4}{|c|}{$\%$} \\
\hline & $1^{\mathrm{a}} \mathrm{C}$ & $2^{\mathrm{a}} \mathrm{C}$ & $1^{\mathrm{a}} \mathrm{C}$ & $2^{\mathrm{a} C}$ \\
\hline Média & 2,0 & 2,8 & 3,5 & 4,5 \\
\hline Mínimo & 0,1 & 0,1 & 0,2 & 0,2 \\
\hline Máximo & 2,7 & 3,8 & 4,9 & 6,0 \\
\hline
\end{tabular}

Tabela 10 - Retenção dos gases (camada com capim Massai, duas campanhas)

\begin{tabular}{|c|c|c|c|c|c|c|}
\hline \multirow{2}{*}{\multicolumn{3}{|c|}{ Variável Calculada }} & \multicolumn{2}{|c|}{$\mathrm{CH}_{4}$} & \multicolumn{2}{|c|}{$\mathrm{CO}_{2}$} \\
\hline & & & $1^{a} \mathrm{C}$ & $2^{a} \mathrm{C}$ & $1^{a} \mathrm{C}$ & $2^{a} \mathrm{C}$ \\
\hline Média & \multirow{3}{*}{ mássico } & \multirow{3}{*}{$\mathrm{gm}^{-2} \cdot \mathrm{s}^{-1}$} & $1,8 \times 10^{-3}$ & $2,5 \times 10^{-3}$ & $8,5 \times 10^{-3}$ & $1,1 \times 10^{-2}$ \\
\hline Mínimo & & & 0,0 & 0,0 & 0,0 & 0,0 \\
\hline Máximo & & & $6,3 \times 10^{-3}$ & $1,4 \times 10^{-2}$ & $3,4 \times 10^{-2}$ & $3,9 \times 10^{-2}$ \\
\hline Média & \multirow{2}{*}{ volumétrico } & \multirow{2}{*}{$\mathrm{m} 3 \mathrm{~m}^{-2} \cdot \mathrm{s}^{-1}$} & $2,8 \times 10^{-6}$ & $4,1 \times 10^{-6}$ & $4,9 \times 10^{-6}$ & $6,2 \times 10^{-6}$ \\
\hline Máximo & & & $1,0 \times 10^{-5}$ & $2,2 \times 10^{-5}$ & $2,0 \times 10^{-5}$ & $2,3 \times 10^{-5}$ \\
\hline
\end{tabular}

Tabela 11 - Fluxos mássicos e volumétricos (camada com capim Massai, duas campanhas) 


\begin{tabular}{|c|c|c|c|c|c|c|c|c|}
\hline \multicolumn{9}{|c|}{ Dados da semana de monitoramento (\%) } \\
\hline \multirow{2}{*}{ Variável Calculada } & \multicolumn{2}{|c|}{$\mathrm{CH}_{4}$} & \multicolumn{2}{|c|}{$\mathrm{CO}_{2}$} & \multicolumn{2}{|c|}{$\mathrm{O}_{2}$} & \multirow{2}{*}{$\frac{\mathrm{OG}}{1^{a} \mathrm{C}}$} & \multirow{2}{*}{$\frac{\mathrm{OG}}{2^{a} \mathrm{C}}$} \\
\hline & $1^{a} \mathrm{C}$ & $2^{a} \mathrm{C}$ & $1^{a} \mathrm{C}$ & $2^{a} \mathrm{C}$ & $1^{a} \mathrm{C}$ & $2^{a} \mathrm{C}$ & & \\
\hline Moda & 7,5 & 10,5 & 4,0 & 13,3 & 10,3 & 7,3 & 71,2 & 72,0 \\
\hline Mínimo & 0,3 & 0,4 & 0,3 & 0,5 & 6,1 & 4,4 & 71,1 & 65,5 \\
\hline Máximo & 8,0 & 11,2 & 14,6 & 17,8 & 10,6 & 8,9 & 89,0 & 90,4 \\
\hline Desvio padrão & 2,3 & 3,3 & 4,0 & 4,9 & 1,3 & 1,3 & 5,3 & 7,2 \\
\hline Aumento da média & \multicolumn{2}{|c|}{2,4} & \multicolumn{2}{|c|}{2,7} & & \\
\hline Redução da média & \multicolumn{2}{|c|}{-} & \multicolumn{2}{|c|}{ - } & \multicolumn{2}{|c|}{1,7} & \multicolumn{2}{|c|}{3,4} \\
\hline
\end{tabular}

Tabela 12 - Concentrações dos gases (camada com capim Andropogon, duas campanhas)

\begin{tabular}{l|c|c|c|c}
\multirow{2}{*}{ Variável Calculada } & \multicolumn{2}{|c|}{$\mathrm{CH}_{4}$} & \multicolumn{2}{c}{$\mathrm{CO} 2$} \\
\cline { 2 - 5 } & \multicolumn{4}{|c}{$\%$} \\
\cline { 2 - 5 } & $1^{\text {a }} C$ & $2^{\text {a }} C$ & $1^{\text {a }} C$ & $2^{\text {a } C}$ \\
\hline Média & 1,1 & 1,5 & 1,9 & 2,5 \\
\hline Mínimo & 0,1 & 0,1 & 0,0 & 0,1 \\
\hline Máximo & 2,4 & 3,4 & 3,7 & 4,6
\end{tabular}

Tabela 13 - Retenção dos gases (camada com capim Andropogon, duas campanhas)

\begin{tabular}{|c|c|c|c|c|c|c|}
\hline \multirow{2}{*}{\multicolumn{3}{|c|}{ Variável Calculada }} & \multicolumn{2}{|c|}{$\mathrm{CH}_{4}$} & \multicolumn{2}{|c|}{$\mathrm{CO}_{2}$} \\
\hline & & & $1^{a} \mathrm{C}$ & $2^{a} \mathrm{C}$ & $1^{a} \mathrm{C}$ & $2^{a} \mathrm{C}$ \\
\hline Média & \multirow{3}{*}{ mássico } & \multirow{3}{*}{$\mathrm{gm}^{-2} \cdot \mathrm{s}^{-1}$} & $2,3 \times 10^{-3}$ & $3,2 \times 10-3$ & $1,1 \times 10^{-2}$ & $1,4 \times 10^{-2}$ \\
\hline Mínimo & & & 0,0 & 0,0 & 0,0 & 0,0 \\
\hline Máximo & & & $8,3 \times 10^{-3}$ & $1,6 \times 10^{-2}$ & $4,3 \times 10^{-2}$ & $5,7 \times 10^{-2}$ \\
\hline Média & \multirow{2}{*}{ volumétrico } & \multirow{2}{*}{$\mathrm{m} 3 \mathrm{~m}^{-2} \cdot \mathrm{s}^{-1}$} & $3,6 \times 10^{-6}$ & $5,2 \times 10^{-6}$ & $6,2 \times 10^{-6}$ & $7,9 \times 10^{-6}$ \\
\hline Máximo & & & $1,3 \times 10^{-5}$ & $2,5 \times 10^{-5}$ & $2,5 \times 10^{-5}$ & $3,3 \times 10^{-5}$ \\
\hline
\end{tabular}

Tabela 14 - Fluxos mássicos e volumétricos (camada com capim Andropogon, duas campanhas)

de $\mathrm{CH}_{4}$ foi $0,3\left({ }^{\mathrm{a}} \mathrm{C}\right)$ e $0,4 \%\left(2^{\mathrm{a}} \mathrm{C}\right)$ e a maior 6,3 e $8,8 \%$ entre as campanhas. Para o $\mathrm{CO}_{2}$ (menores valores: 0,5 e 0,6\%; maiores valores: $11,5 \mathrm{e}$ $14,0 \%$ ). Para o $\mathrm{O}_{2}$ (menores valores: 4,8 e $3,4 \%$; maiores valores: 8,4 e $7,1 \%$ ). Observou-se um aumento na dispersão dos dados referentes às concentrações de todos os gases de uma campanha para outra, exceto para o oxigênio.

Observou-se retenção dos dois gases de interesse pela camada de cobertura cultivada com capim Massai nas duas campanhas (medida pela diferença entre a concentração no dreno e a con- centração na camada), como apresenta a Tabela 10. Já os fluxos estão consolidados na Tabela 11.

Os gases emitidos pelo solo cultivado com capim Andropogon foram compostos, na primeira campanha, em média, por $9,7 \%$ de $\mathrm{CO}_{2}, 5,5 \%$ de $\mathrm{CH}_{4}, 8,2 \%$ de $\mathrm{O}_{2}$ e $76,7 \%$ de outros gases (identificados desta forma pelo equipamento). Na segunda campanha, houve um aumento na concentração dos dois principais gases de interesse $\left(\mathrm{CO}_{2}\right.$ e $\left.\mathrm{CH}_{4}\right)$ e redução na concentração de $\mathrm{O}_{2}$ e de outros gases (média): 12,4\% de $\mathrm{CO}_{2}, 7,8 \%$ de $\mathrm{CH}_{4}, 6,5 \%$ de $\mathrm{O}_{2}$ e $73,3 \%$ de outros gases. Outras 
variáveis calculadas estão na Tabela 12 .

Como se observa na Tabela 12 , da primeira para a segunda campanha de monitoramento a concentração de $\mathrm{CH}_{4}$ que mais se repetiu no interior da placa (Moda) foi 7,5 $\left(1^{\mathrm{a}} \mathrm{C}\right)$ e $10,5 \%\left(2^{\mathrm{a}} \mathrm{C}\right)$, para o $\mathrm{CO}_{2}$ foi 4,0 e $13,3 \%$ e para $\mathrm{O}_{2}$ foi 10,3 e $7,3 \%$. Observou-se ainda que a menor concentração de $\mathrm{CH}_{4}$ foi $0,3\left(1^{\mathrm{a}} \mathrm{C}\right)$ e $0,4 \%\left(2^{\mathrm{a}} \mathrm{C}\right)$ e a maior 8,0 e $11,2 \%$ entre as campanhas. Para o $\mathrm{CO}_{2}$ (menores valores: 0,3 e $0,5 \%$; maiores valores: 14,6 e 17,8\%). Para o $\mathrm{O}_{2}$ (menores valores: 6,1 e 4,4\%; maiores valores: 10,6 e $8,9 \%$ ). Observou-se um aumento na dispersão dos dados referentes às concentrações de todos os gases de uma campanha para outra, exceto para o oxigênio.

Observou-se retenção dos dois gases de interesse pela camada de cobertura cultivada com capim Andropogon nas duas campanhas (medida pela diferença entre a concentração no dreno e a concentração na camada), como apresenta a Tabela 13. Já os fluxos estão consolidados na Tabela 14 .

Os gases emitidos pelo solo cultivado com a grama Bermuda foram compostos, na primeira campanha, em média, por $10,1 \%$ de $\mathrm{CO}_{2}, 5,7 \%$ de $\mathrm{CH}_{4}, 8,3 \%$ de $\mathrm{O}_{2}$ e $76,0 \%$ de outros gases (iden-

\begin{tabular}{|c|c|c|c|c|c|c|c|c|}
\hline \multicolumn{9}{|c|}{ Dados da semana de monitoramento (\%) } \\
\hline \multirow{2}{*}{ Variável Calculada } & \multicolumn{2}{|c|}{$\mathrm{CH}_{4}$} & \multicolumn{2}{|c|}{$\mathrm{CO}_{2}$} & \multicolumn{2}{|c|}{$\mathrm{O}_{2}$} & \multirow{2}{*}{$\begin{array}{c}\text { OG } \\
\frac{1^{a} C}{}\end{array}$} & \multirow{2}{*}{$\frac{O G}{2^{a}}$} \\
\hline & $1^{a} \mathrm{C}$ & $2^{a} \mathrm{C}$ & $1^{a} \mathrm{C}$ & $2^{a} \mathrm{C}$ & $1^{a} \mathrm{C}$ & $2^{a} \mathrm{C}$ & & \\
\hline Moda & 7,6 & 10,9 & 11,9 & 16,4 & 9,3 & 7,9 & 70,6 & 89,5 \\
\hline Mínimo & 0,1 & 0,1 & 0,3 & 0,5 & 6,2 & 4,4 & 70,5 & 64,8 \\
\hline Máximo & 8,2 & 11,5 & 14,9 & 18,2 & 10,9 & 9,2 & 89,0 & 90,5 \\
\hline Desvio padrão & 2,4 & 3,5 & 4,3 & 5,3 & 1,3 & 1,2 & 5,6 & 7,8 \\
\hline Aumento da média & \multicolumn{2}{|c|}{2,5} & \multicolumn{2}{|c|}{2,8} & & \\
\hline Redução da média & \multicolumn{2}{|c|}{-} & & \multicolumn{2}{|c|}{1,7} & \multicolumn{2}{|c|}{3,5} \\
\hline
\end{tabular}

Tabela 15 - Concentrações dos gases (camada com grama Bermuda, duas campanhas)

\begin{tabular}{l|c|c|c|c}
\multirow{2}{*}{ Variável Calculada } & \multicolumn{2}{|c|}{$\mathrm{CH}_{4}$} & \multicolumn{2}{c}{$\mathrm{CO} 2$} \\
\cline { 2 - 5 } & \multicolumn{4}{|c}{$\%$} \\
\cline { 2 - 5 } & $1^{a} C$ & $2^{a} C$ & $1^{a} C$ & $2^{a} C$ \\
\hline Média & 0,9 & 1,3 & 1,6 & 2,0 \\
\hline Mínimo & 0,1 & 0,2 & 0,0 & 0,1 \\
\hline Máximo & 2,6 & 3,6 & 4,2 & 5,7
\end{tabular}

Tabela 16 - Retenção dos gases (camada com grama Bermuda, duas campanhas)

\begin{tabular}{|c|c|c|c|c|c|c|}
\hline \multirow{2}{*}{\multicolumn{3}{|c|}{ Variável Calculada }} & \multicolumn{2}{|c|}{$\mathrm{CH}_{4}$} & \multicolumn{2}{|c|}{$\mathrm{CO}_{2}$} \\
\hline & & & \multirow{2}{*}{$\frac{1^{a} C}{2,3 \times 10^{-3}}$} & \multirow{2}{*}{$\begin{array}{c}2^{a} \mathrm{C} \\
3,4 \times 10^{-3}\end{array}$} & \multirow{2}{*}{$\begin{array}{c}1^{a} \mathrm{C} \\
1,1 \times 10^{-2}\end{array}$} & \multirow{2}{*}{$\frac{2^{a} \mathrm{C}}{1,4 \times 10^{-2}}$} \\
\hline Média & \multirow{3}{*}{ mássico } & \multirow{3}{*}{$\mathrm{gm}^{-2} \cdot \mathrm{s}^{-1}$} & & & & \\
\hline Mínimo & & & 0,0 & 0,0 & 0,0 & 0,0 \\
\hline Máximo & & & $7,3 \times 10^{-3}$ & $2,3 \times 10^{-2}$ & $4,3 \times 10^{-2}$ & $5,1 \times 10^{-2}$ \\
\hline Média & \multirow{2}{*}{ volumétrico } & \multirow{2}{*}{$\mathrm{m} 3 \mathrm{~m}^{-2} \cdot \mathrm{s}^{-1}$} & $3,7 \times 10^{-6}$ & $5,4 \times 10^{-6}$ & $6,4 \times 10^{-6}$ & $8,2 \times 10^{-6}$ \\
\hline Máximo & & & $1,2 \times 10^{-5}$ & $3,7 \times 10^{-5}$ & $2,5 \times 10^{-5}$ & $3,0 \times 10^{-5}$ \\
\hline
\end{tabular}

Tabela 17 - Fluxos mássicos e volumétricos (camada com grama Bermuda, duas campanhas) 
tificados desta forma pelo equipamento). $\mathrm{Na}$ segunda campanha, houve um aumento na concentração dos dois principais gases de interesse $\left(\mathrm{CO}_{2}\right.$ e $\left.\mathrm{CH}_{4}\right)$ e redução na concentração de $\mathrm{O}_{2}$ e de outros gases (média): 12,9\% de $\mathrm{CO}_{2}, 8,1 \%$ de $\mathrm{CH}_{4}, 6,6 \%$ de $\mathrm{O}_{2}$ e $72,4 \%$ de outros gases. Outras variáveis calculadas estão na Tabela 15.

Como se observa na Tabela 15, da primeira para a segunda campanha de monitoramento a concentração de $\mathrm{CH}_{4}$ que mais se repetiu no interior da placa (Moda) foi 7,6 $\left(1^{\mathrm{a}} \mathrm{C}\right)$ e $10,9 \%\left(2^{\mathrm{a}} \mathrm{C}\right)$, para o $\mathrm{CO}_{2}$ foi 11,9 e $16,4 \%$ e para $\mathrm{O}_{2}$ foi 9,3 e $7,9 \%$. Observou-se ainda que a menor concentra- ção de $\mathrm{CH}_{4}$ foi $0,1\left(1^{\mathrm{a}} \mathrm{C}\right)$ e $0,1 \%\left(2^{\mathrm{a}} \mathrm{C}\right)$ e a maior 8,2 e $11,5 \%$ entre as campanhas. Para o $\mathrm{CO}_{2}$ (menores valores: 0,3 e 0,5\%; maiores valores: 14,9 e 18,2\%). Para o $\mathrm{O}_{2}$ (menores valores: 6,2 e 4,4\%; maiores valores: 10,9 e 9,2\%). Observou-se um aumento na dispersão dos dados referentes às concentrações de todos os gases de uma campanha para outra, exceto para o oxigênio.

Observou-se retenção dos dois gases de interesse pela camada de cobertura cultivada com capim Andropogon nas duas campanhas (medida pela diferença entre a concentração no dreno e a concentração na camada), como apresenta a

\begin{tabular}{|c|c|c|c|c|c|c|c|c|}
\hline \multicolumn{9}{|c|}{ Dados da semana de monitoramento (\%) } \\
\hline \multirow{2}{*}{ Variável Calculada } & \multicolumn{2}{|c|}{$\mathrm{CH}_{4}$} & \multicolumn{2}{|c|}{$\mathrm{CO}_{2}$} & \multicolumn{2}{|c|}{$\mathrm{O}_{2}$} & \multirow{2}{*}{$\begin{array}{l}\text { OG } \\
1^{a} \mathrm{C}\end{array}$} & \multirow{2}{*}{$\frac{\mathrm{OG}}{2^{a} \mathrm{C}}$} \\
\hline & $1^{a} \mathrm{C}$ & $2^{a} \mathrm{C}$ & $1^{a} \mathrm{C}$ & $2^{a} \mathrm{C}$ & $1^{a} \mathrm{C}$ & $2^{a} \mathrm{C}$ & & \\
\hline Moda & 7,9 & 10,6 & 13,2 & 19,1 & 8,8 & 5,4 & 68,9 & 66,2 \\
\hline Mínimo & 0,2 & 0,3 & 0,6 & 0,9 & 1,0 & 0,8 & 68,8 & 62,8 \\
\hline Máximo & 8,6 & 12,1 & 15,7 & 19,2 & 11,5 & 9,7 & 88,0 & 89,4 \\
\hline Desvio padrão & 2,4 & 3,4 & 4,1 & 5,0 & 1,6 & 1,5 & 5,5 & 7,4 \\
\hline Aumento da média & \multicolumn{2}{|c|}{2,7} & \multicolumn{2}{|c|}{3,2} & & \\
\hline Redução da média & & & & \multicolumn{2}{|c|}{1,8} & \multicolumn{2}{|c|}{4,0} \\
\hline
\end{tabular}

Tabela 18 - Concentrações dos gases (camada com capim Buffel, duas campanhas)

\begin{tabular}{|c|c|c|c|c|}
\hline \multirow{3}{*}{ Variável Calculada } & \multicolumn{2}{|c|}{$\mathrm{CH}_{4}$} & \multicolumn{2}{|c|}{$\mathrm{CO} 2$} \\
\hline & \multicolumn{4}{|c|}{$\%$} \\
\hline & $1^{a} C$ & $2^{a} C$ & $1^{a} C$ & $2^{a} C$ \\
\hline Média & 0,4 & 0,6 & 0,5 & 0,6 \\
\hline Mínimo & 0,1 & 0,1 & 0,1 & 0,1 \\
\hline Máximo & 1,5 & 2,1 & 0,7 & 0,8 \\
\hline
\end{tabular}

Tabela 19 - Retenção dos gases (camada com capim Buffel, duas campanhas)

\begin{tabular}{|c|c|c|c|c|c|c|}
\hline \multirow{2}{*}{\multicolumn{3}{|c|}{ Variável Calculada }} & \multicolumn{2}{|c|}{$\mathrm{CH}_{4}$} & \multicolumn{2}{|c|}{$\mathrm{CO}_{2}$} \\
\hline & & & $1^{a} \mathrm{C}$ & $2^{a} \mathrm{C}$ & $1^{a} \mathrm{C}$ & $2^{a} \mathrm{C}$ \\
\hline Média & \multirow{3}{*}{ mássico } & \multirow{3}{*}{$\mathrm{gm}^{-2} \cdot \mathrm{s}^{-1}$} & $2,4 \times 10^{-3}$ & $3,5 \times 10^{-3}$ & $1,2 \times 10^{-2}$ & $1,5 \times 10^{-2}$ \\
\hline Mínimo & & & 0,0 & 0,0 & 0,0 & 0,0 \\
\hline Máximo & & & $8,3 \times 10^{-3}$ & $1,8 \times 10^{-2}$ & $4,6 \times 10^{-2}$ & $5,2 \times 10^{-2}$ \\
\hline Média & \multirow{2}{*}{ volumétrico } & \multirow{2}{*}{$\mathrm{m} 3 \mathrm{~m}^{-2} \cdot \mathrm{s}^{-1}$} & $3,9 \times 10^{-6}$ & $5,6 \times 10^{-6}$ & $6,7 \times 10^{-6}$ & $8,5 \times 10^{-6}$ \\
\hline Máximo & & & $1,3 \times 10^{-5}$ & $2,8 \times 10^{-5}$ & $2,7 \times 10^{-5}$ & $3,0 \times 10^{-5}$ \\
\hline
\end{tabular}

Tabela 20 - Fluxos mássicos e volumétricos (camada com capim Buffel, duas campanhas) 
Tabela 16. Já os fluxos estão consolidados na Tabela 17 .

Os gases emitidos pelo solo cultivado com o capim Buffel foram compostos, na primeira campanha, em média, por $11,1 \%$ de $\mathrm{CO}_{2}, 6,1 \%$ de $\mathrm{CH}_{4}$, $8,6 \%$ de $\mathrm{O}_{2}$ e $74,1 \%$ de outros gases (identificados desta forma pelo equipamento). Na segunda campanha, houve um aumento na concentração dos dois principais gases de interesse $\left(\mathrm{CO}_{2} \mathrm{e} \mathrm{CH}_{4}\right)$ e redução na concentração de $\mathrm{O}_{2}$ e de outros gases (média): 14,3\% de $\mathrm{CO}_{2}, 8,8 \%$ de $\mathrm{CH}_{4}, 6,8 \%$ de $\mathrm{O}_{2}$ e 70,1\% de outros gases. Outras variáveis calculadas estão na Tabela 18 .

Como se observa na Tabela 18 , da primeira para a segunda campanha de monitoramento a concentração de $\mathrm{CH}_{4}$ que mais se repetiu no interior da placa (Moda) foi $7,9\left(1^{\mathrm{a}} \mathrm{C}\right)$ e $10,6 \%\left(2^{\mathrm{a}} \mathrm{C}\right)$, para o $\mathrm{CO}_{2}$ foi 13,2 e $19,1 \%$ e para $\mathrm{O}_{2}$ foi 8,8 e $5,4 \%$. Observou-se ainda que a menor concentração de $\mathrm{CH}_{4}$ foi $0,2\left(1^{\mathrm{a}} \mathrm{C}\right)$ e $0,3 \%\left(2^{\mathrm{a}} \mathrm{C}\right)$ e a maior 8,6 e $12,1 \%$ entre as campanhas. Para o $\mathrm{CO}_{2}$ (menores valores: 0,6 e 0,9\%; maiores valores: 15,7 e $19,2 \%$ ). Para o $\mathrm{O}_{2}$ (menores valores: 1,0 e 0,8\%; maiores valores: 11,5 e $9,7 \%$ ).

Observou-se um aumento na dispersão dos dados referentes às concentrações de todos os gases de uma campanha para outra, exceto para o oxigênio. Observou-se retenção dos dois gases de interesse pela camada de cobertura cultivada com capim Andropogon nas duas campanhas (medida pela diferença entre a concentração no dreno e a concentração na camada), como apresenta a Tabela 19. Já os fluxos estão consolidados na Tabela 20.

Como se observa, o capim Mombaça apresentou um melhor desempenho em relação aos demais, provavelmente, por possuir uma maior capacidade de (i) sequestrar carbono, (ii) aumentar a saturação do solo em função do crescimento da umidade na zona das raízes, (iii) reduzir os espaços vazios do solo (impedimento mecânico) provocado pelas raízes ou outros processos ainda pouco estudados.

Considerando tais questões, estudos voltados à redução das emissões de $\mathrm{CH}_{4}$ e $\mathrm{CO}_{2}$ pela cobertura dos aterros sanitários complementam os temas já pesquisados no Brasil e podem auxiliar (i) no desenvolvimento de projetos de aproveitamento energético do metano e de créditos de carbono mais seguros e econômicos, (ii) na recuperação paisagística das áreas de disposição de RSU (com consequente redução do impacto vi- sual e reintegração da área do aterro a paisagem vizinha) e (iii) no sequestro de carbono.

$\mathrm{O}$ uso de gramíneas sobre a cobertura final de aterros sanitários contribui para: i) redução das fissuras, dos processos erosivos e da entrada de água e ar no maciço de RSU, ii) aumento da estabilidade dos taludes, iii) recuperação paisagística, iv) sequestro de carbono, v) redução da suspensão de partículas (poeira) e vi) regulação da temperatura.

Além disso, o processo de revegetação da superfície dos aterros sanitários ainda é pouco pesquisado no Brasil (LONDE e BITAR, 2011) e a remediação dessas áreas com a utilização de espécies vegetais, além do efeito visual e protetor, é geralmente uma exigência legal e um compromisso social que precisam ser executados, criando uma enorme demanda tecnológica, oportunidades de pesquisa científica [...] (LONDE e BITAR, 2011).

Oliveira (2004) lembra que a revegetação de um aterro é a alternativa de recuperação da área degradada mais barata e, na atualidade, existe uma grande demanda por áreas verdes nas cidades. Assim sendo, resultados que apontem desenvolvimento satisfatório dos cultivos escolhidos podem significar, senão sozinhos, o início de um processo de sucessão ecológica, onde o solo da camada de cobertura do aterro sanitário passará, aos poucos, a favorecer o desenvolvimento de espécies superiores e mais exigentes, justificando, portanto esse tipo de investigação.

\section{Conclusão}

O tempo de aterramento dos resíduos sólidos na $\mathrm{CE}$ favoreceu o aumento nas concentrações dos gases $\mathrm{CH}_{4}$ e $\mathrm{CO}_{2}$ já que os resultados da segunda campanha foram maiores, em concentração e em fluxo, que os resultados da primeira campanha.

O comportamento das emissões pela cobertura foi semelhante nas duas campanhas, ou seja, houve um elevado acréscimo da concentração dos gases de interesse até certo ponto do ensaio (em minutos) seguido de um crescimento mais lento, com tendência da curva ficar paralela ao eixo do tempo (constante).

A concentração do $\mathrm{CO}_{2}$, em todas as situações, esteve acima da concentração do gás $\mathrm{CH}_{4}$, mostrando que a $\mathrm{CE}$ continha resíduos sólidos na fase ácida de digestão, também verificada pela qualidade do chorume, e esses resultados estão 
dentro dos intervalos constantes na literatura.

Os resultados dos fluxos indicam que os maiores valores aconteceram pela tarde, provavelmente porque o solo, nesse turno, esteve menos saturado e isso facilita a percolação vertical dos gases. Além disso, os dados apresentaram maior correlação (menor dispersão) no turno da manhã.

O fluxo médio de $\mathrm{CO}_{2}$ durante o turno da manhã (em g.m ${ }^{-2}$.s) foi 4,4 vezes maior que o fluxo de $\mathrm{CH}_{4}$ e pela tarde essa diferença aumentou para 5,0 vezes. Em termos volumétricos essa diferença foi menor (de 1,8 vezes) tanto na manhã quanto na tarde.

O plantio das gramíneas sobre a cobertura da CE reduziu as emissões de gases pelo solo e esse resultado pode inaugurar localmente uma linha de pesquisa sobre o tema, já que além da redução da emissão de gases de efeito estufa pelos aterros, os cultivos representaram o início de uma recuperação paisagística da área, reduzindo o impacto visual.

Entre os cultivos, o capim Mombaça permitiu os menores fluxos de $\mathrm{CH}_{4}$ e $\mathrm{CO}_{2}$ (maior retenção), tanto mássico quanto volumétrico, em relação ao "branco" e o capim Buffel foi o que apresentou maiores fluxos (menor retenção).

\section{Referências}

ABICHOU et al. (2006) Methane flux and oxidation at two types of intermediate landfill covers. Waste Management, v.26, n.11, p.1305-1312.

AYE, L.; WIDJAYA, E. R. (2006) Environmental and economic analyses of waste disposal options for traditional markets in Indonesia. Waste Management, v.26, n.10, p.1180-1191.

BERTO NETO, J. (2009) Medidas da emissão de gases em oito aterros de resíduos sólidos urbanos do estado de São Paulo - Brasil. Tese (Doutorado em Ciências da Engenharia Ambiental), Escola de Engenharia de São Carlos, Universidade de São Paulo, 588p.

CAPACCIONI et al. (2011) Effects of a temporary HDPE cover on landfill gas emissions: multiyear evaluation with the static chamber approach at an Italian landfill. Waste Management, v.31, n.5, p.956-965.

CARVALHO, M. M.; FREITAS, V. P.; ANDRADE, A. C. (1995) Crescimento inicial de cinco gramíneas tropicais em um sub-bosque de angico-vermelho.
Pasturas Tropicales, v.17, n.1, p.24-30.

DANTAS NETO et al. (2000) Influência da precipitação e idade da planta na produção e composição química do capim Buffel. Pesquisa Agropecuária Brasileira, v.35, n.9, p.1867-1874.

FERNANDES, J. G. (2009) Estudo da emissão de biogás em um aterro sanitário experimental. Dissertação (Mestrado em Saneamento, Meio Ambiente e Recursos Hídricos), Universidade Federal de Minas Gerais, 116p.

GEORGAKI et al. (2008) Evaluating the use of electrical resistivity imaging technique for improving $\mathrm{CH} 4$ and $\mathrm{CO} 2$ emission rate estimations in landfills. Science of the total environment. v.389, n.2-3, p.522-531.

GOMES, L. P.; MARTINS, F. B. (2003) Projeto, implantação e operação de aterros sustentáveis de resíduos sólidos urbanos para municípios de pequeno porte. In: CASTILHOS JÚNIOR, A. B. (Coord.). Resíduos sólidos urbanos: aterro sustentável para municípios de pequeno porte. Rio de Janeiro: ABES, RiMa, Projeto PROSAB, p.51-102.

GUEDES, V. P. (2007) Estudo do fluxo de gases através do solo de cobertura de aterro de resíduos sólidos urbanos. Dissertação (Mestrado em Engenharia Civil), Universidade Federal do Rio de Janeiro, Rio de Janeiro, 117p.

HEDGE, U.; CHAN, T.; YANG, S. (2003) Methane and carbon dioxide emissions from Shan-Chu-ku landfill site in northern Taiwan. Chemosphere, v.52, n.8, p.1275-1285.

HUBER-HUMER, M.; LECHNER, P. (1999) Alternative approach to the elimination of greenhouse gases from old landfills. Waste Management, v.17, n.6, p.443-452.

ISHIGAKI et al. (2008) Estimation and field measurement of methane emission from waste landfills in Hanoi, Vietnam. Journal of Material Cycles and Waste Management, v.10, n.2, p.165172. 
JHA et al. (2008) Greenhouse gas emissions from municipal solid waste management in Indian mega-cities: a case study of Chennai landfill sites. Chemosphere, v.71, n.4, p.750-758.

JOHANNESSEN, L. M. (1999) Guidance note on recuperation of landfill gas from municipal solid waste landfills. The International Bank for Reconstruction and Development/THE WORLD BANK, Working Paper Series, Washington, D.C., 23p.

JOHNSSON, E. (2010) Correlation between methane concentration and - emission from old landfills in Sweden. Thesis (Master Environmental Engineering). Lund University, 71p.

LAURETTI, R. S. (2003) Implantação de gramados por sementes. In: I SIGRA - Simpósio sobre gramados: "produção, implantação e manutenção”, Anais ‥ Botucatu: SIGRA, 21p.

LAURILA et al. (2006) Methane emissions from three different kinds of landfills measured by the micrometeorological eddy-covariance method. In: IV Intercontinental Landfill Research Symposium, Abstract $\cdots$ Gällivare, p.1-5.

LOPES et al. (2010) Camadas de cobertura metanotróficas como alternativas para gerenciamento de gases de efeito estufa em aterros sanitários. Holos, v.4, n.25, p.3-18.

MACIEL, F. J. (2003) Estudo da geração, percolação e emissão de gases no aterro de resíduos sólidos da Muribeca/PE. Dissertação (Mestrado em Ciências em Engenharia Civil), Universidade Federal de Pernambuco, Recife, 173p.

MARIANO, M. O. H.; JUCÁ, J. F. T. (2010) Ensaios de campo para determinação de emissões de biogás em camadas de cobertura de aterros de resíduos sólidos. Nota Técnica, Engenharia Sanitária e Ambiental, v.15, n.3, p.223-228.

MESQUITA et al. (2010) Teores críticos de fósforo no solo e características morfogênicas de Panicum maximum cultivares Mombaça e Tanzânia-1 e Brachiaria híbrida Mulato sob aplicação de fósforo. Revista Brasileira de Saúde e Produção Animal, v.11, n.2, p.292-302.
MILKE, M. W.; HOLMAN, J.; KHIRE, M. (2006) Use of gas flux measurements to infer well capture effectiveness. IV Intercontinental Landfill Research Symposium, Abstract $\cdots$ Gällivare, p.138-139.

NAVA-MARTINEZ, E. C.; GARCIA-FLORES, E.; WAKIDA, F. T. (2011) Surface methane emission in a former dumpsite in Tijuana, México. International Journal of Environmental Science Research. v.5, n.3, p.621-626.

OLIVEIRA, C. N. Recuperação ambiental de aterros sanitários na região metropolitana de Campinas: revegetação e uso futuro. 2004. 88p. Dissertação (Mestrado em Engenharia Civil). Universidade Estadual de Campinas, Campinas, 2004.

PARK, J. W.; SHIN, H. C. (2001) Surface emission of landfill gas from solid waste landfill. Atmospheric Environment, v.35, p.3445-3451.

PEREIRA, A. R. (2006) Como selecionar plantas para áreas degradadas e controle de erosão. Belo Horizonte, 1. ed. 88p.

POPOV, V. (2005) A new landfill system for cheaper landfill gas purification. Renewable Energy, v.30, n.7, p.1021-1029.

SCHEUTZ et al. (2008) Atmospheric emissions and attenuation of non-methane organic compounds in cover soils at a French landfill. Waste Management, v.28, n.11, p.1892-1908.

STERN et al. (2007) Use of a biologically active cover to reduce landfill methane emissions and enhance methane oxidation. Waste Management, v.27, n.9, p.1248-1258.

VERAS et al. (2010) Produção de biomassa e estrutura do pasto de capim Andropogon em sistema silvipastoril e monocultura. Arquivos Brasileiros de Medicina Veterinária e Zootecnia, v.62, n.1, p.200-207.

ZHANG, H.; HE, P.; SHAO, L. (2008) Methane emissions from MSW landfill with sandy soil covers under leachate recirculation and subsurface irrigation. Atmospheric Environment, v.42, n.22, p. $5579-5588$. 